\title{
A CONVIVÊNCIA ENTRE O PROGRAMA ESCOLA GUAICURU - VIVENDO UMA NOVA LIÇÃO E O PROGRAMA MELHORIA E EXPANSÃO DO ENSINO MÉDIO: (Promed/Escola Jovem) no estado de Mato Grosso do Sul
}

\author{
THE COEXISTENCE OF THE ESCOLA GUAICURU - \\ VIVENDO UMA NOVA LIÇÃO PROGRAM AND THE SECON- \\ DARY SCHOOL IMPROVEMENT AND EXPANSION \\ PROGRAM: (Promed/Escola Jovem) in the State of \\ Mato Grosso do Sul (Brazil)
}

\author{
Maria Dilnéia Espíndola Fernandes* \\ Jorge Luís D'Avila*
}

\begin{abstract}
Resumo
O artigo analisa a convivência entre o Programa Escola Guaicuru - Vivendo Uma Nova Lição e o Programa Melhoria e Expansão do Ensino Médio (Promed/Escola Jovem) no Estado de Mato Grosso do Sul, no período de 1999 a 2006. Ressaltou-se que, no contexto de operacionalização da Lei n. 9.424/1996 (Fundef), o Estado teve que transferir recursos para seus municípios, situação que o levou a buscar novas fontes de financiamento para o Ensino Médio, tal como o Promed, proposto e coordenado pelo Ministério de Educação e Cultura (MEC). A pesquisa tomou como fonte a legislação educacional, documentos produzidos em âmbito federal e estadual e a literatura pertinente à temática. Constatou-se que a convivência entre o programa Escola Guaicuru - Vivendo Uma Nova Lição e o Promed distorceu os pressupostos da política educacional estadual porque tinham orientações antagônicas. Como o estado não cumpriu totalmente as metas do Promed perdeu recursos para investir no Ensino Médio.

Palavras-chave: Política Educacional. Ensino Médio. Financiamento da educação.
\end{abstract}

\begin{abstract}
The present article analyzes the coexistence of the Escola Guaicuru - Vivendo Uma Nova Lição Program and the Secondary School Improvement and Expansion Program (Promed/Escola Jovem) during the years 1999 to 2006. It emphasizes that, according to the Law $n^{\circ}$. 9.424/1996 (Fundef), the state is responsible for transferring financial resources to its municipalities. As a result, the state government had to seek new sources of funding for the Secondary Education, such as the Promed, proposed and coordinated by the Ministry of Education and Culture - MEC. The research was based on the educational legislation, on federal and state government documents and on the relevant literature. It concluded that the coexistence of the Escola Guaicuru - Vivendo uma Nova Lição Program and the Promed distorted the assumptions of the state educational policy because the programs themselves had different orientations. As the state did not fully comply with the goals of the Promed, it could not receive the necessary resources to invest in the secondary school. Keywords: Educational Policy. Secondary School. Education Funding.
\end{abstract}

Introdução

O objetivo deste trabalho foi desvelar a convivência, no âmbito do Ensino Médio, da política educacional, implantada por meio do Programa Escola Guaicuru - Vivendo Uma Nova Lição e a implementação e operacionalização do Programa Melhoria e Expansão do Ensino Médio (Promed/Escola Jovem), proposto e coordenado pelo Ministério de Educação e Cultura (MEC).

Pontua-se que o Programa Escola Guaicuru estabeleceu as diretrizes, princípios, objetivos e metas da política educacional na administração de José Orcírio Miranda dos Santos, o "Zeca do PT", sob um governo com a hegemonia do Partido dos Trabalhadores (PT) em duas gestões consecutivas, no período de 1999 a

\footnotetext{
* Professora do Programa de Pós-Graduação em Educação da Universidade Federal de Mato Grosso do Sul. E-mail: mdilneia@uol.com.br

*** Professor da Rede Municipal de Ensino de Campo Grande, MS. E-mail: davilapersonal@yahoo.com.br
} 
2006. Diante disso, trabalhou-se aqui com a legislação educacional, com documentos produzidos em âmbito federal e estadual e a literatura pertinente a essa temática.

De fato, a política educacional implantada por meio do Programa Escola Guaicuru, tinha como objetivo central a radicalização da democracia na educação por meio "da democratização do acesso, democratização da gestão e qualidade social na educação" (MATO GROSSO DO SUL, 1999a, p. 9), e se colocava como "[...] alternativa na disputa com os projetos neoliberais no campo educacional" (MATO GROSSO DO SUL, 1999a, p. 13), a partir do

[...] compromisso de se construir junto com a sociedade sul-mato-grossense uma escola pública que efetive a democratização do acesso, da democratização da gestão, a permanência e progressão escolar do aluno e a qualidade social da educação que inclui a valorização dos trabalhadores em educação. (MATO GROSSO DO SUL, 1999a, p. 13).

Apesar dos objetivos, dos princípios e das críticas documentados pela Secretaria de Estado de Educação,

[...] a reforma educacional em curso no Brasil, nos anos 1990, colocou para as unidades subnacionais tarefas que tais unidades implementaram, seja por determinação jurídico-legal, como foi o caso das normatizações instituídas a partir da Constituição Federal de 1988, da Lei $n^{\circ}$. 9.424/1996 e da Lei n. 9.394/1996, ou ainda, as determinações/orientações decorrentes dos programas e projetos do Ministério da Educação e Cultura, com vistas a materializar tal reforma. (FERNANDES; D'AVILA, 2008, p. 422).

Assim, embora o forte poder indutor da União (ABRÚCIO, 2010), historicamente construído no âmbito das relações federativas brasileiras e, desse poder ter se acentuado ainda mais nos anos de 1990, sabe-se, contudo, que as unidades subnacionais poderiam manter sua autonomia aliada à interdependência governamental para o exercício da política educacional. Seria uma importante determinação local combinada, ou à revelia do poder central, que poderia resultar em novos marcos para a efetivação da política educacional. Pois,

O Brasil é um país federativo. E um país federativo supõe o compartilhamento do poder e a autonomia relativa das circunscrições federadas em competências próprias de suas iniciativas. Outra suposição de uma organização federativa, decorrente da anterior, é a não-centralização do poder. Isso significa a necessidade de um certo grau de unidade sem amordaçar a diversidade. (CURY, 2002, p. 172).

Não obstante isso, e além de esse ter sido um período em que o estado do Mato Grosso do Sul foi administrado pelos que faziam críticas ao projeto neoliberal de governo e sociedade, o financiamento externo para a Educação não foi percebido como uma das diretrizes desse projeto, dado que o Programa Melhoria e Expansão do Ensino Médio (Promed/Escola Jovem) foi financiado com recursos do Banco Interamericano de Desenvolvimento (BID).

O BID, uma das agências do Banco Mundial, passa a implementar programas da natureza do Promed/Escola Jovem porque, de acordo com Leher (1999, p. 8):

A centralidade adquirida pela educação no discurso do Banco Mundial nos anos 1990 é recente. $\mathrm{Na}$ década de 1960, um vice-presidente do Banco, Robert Gardner afirmou: "nós não podemos emprestar para educação e saúde. Nós somos um banco!". Esta situação começou a mudar na gestão de Woods (1963-1968) e, mais acentuadamente, na presidência de McNamara, quando a ênfase no problema da pobreza fez a educação sobressair entre as prioridades do Banco. Na década de 1970, esta instituição considerava o financiamento às escolas primárias e secundárias de formação geral um contra-senso, defendendo o ensino técnico e profissional, modalidades tidas como mais adequadas às necessidades (presumidas) dos países em desenvolvimento. Na virada neoliberal da década de 1980, a orientação educacional do Banco sofreu uma inflexão em direção ao ensino elementar. A orientação anterior foi então duramente atacada como voluntarista e dispendiosa. Na década de 1990, a inflexão neoliberal não apenas permanece válida como é radicalizada.

Cury (2002, p.179) alertou também que, nos anos 1990:

[...] boa parte dos investimentos em educação não foi contemplada com a poupança interna. Desse modo, o investimento externo acertado junto a Bancos - investimento que é dívida a pagar - foi mais do que um empréstimo. Ele veio acompanhado de critérios contratuais (nem sempre transparentes) e mesmo de metodologias já predefinidas. Se, por um lado, a vinculação orçamentária amortece o impacto deste fator, por outro lado, a dependência a tais liames não pode ser desprezada.

Foi nesse contexto que o Programa Melhoria e Expansão do Ensino Médio (Promed/Escola Jovem) foi compreendido pela Secretaria de Estado de Educação de Mato Grosso do Sul, como uma importante fonte de financiamento para o Ensino Médio estadual.

Registra-se que, no estado do Mato Grosso do Sul, historicamente, o Poder Executivo sempre considerou fundamental preservar as relações institucionais com a União. Nesse sentido, a implantação e operacionalização de programas e projetos oriundos dessa esfera federativa, foram sempre interpretadas como mecanismos de cooperação técnica e financeira, instrumentos que, de acordo com a Secretaria de Estado de Educação, contribuiriam com auxílios 
A convivência entre o Programa Escola Guaicuru - Vivendo Uma Nova Lição e o Programa...

e melhorias para a política educacional estadual. (FERNANDES, 2000). No período de 1999 a 2006 não foi diferente. Embora setores tecnocráticos da Secretaria de Estado de Educação nesse período questionassem a presença dos financiamentos externos para a educação, tais questionamentos não foram suficientes para abalar a ordem historicamente estabelecida nas relações entre estado e União. (FERNANDES, 2008).

Ainda o Programa Melhoria e Expansão do Ensino Médio (Promed/Escola Jovem) foi implantado concomitantemente ao Fundo de Manutenção e Desenvolvimento do Ensino Fundamental e de Valorização do Magistério (Fundef), Lei $n^{\circ}$. 9.424/1996, (BRASIL, 1996a), cuja focalização dos recursos da ordem de $15 \%$ da receita de impostos, dispostos pela Constituição Federal de 1988 (BRASIL, 1988) e normatizado pela Lei de Diretrizes e Bases da Educação Nacional, Lei no. 9.394/1996 (BRASIL, 1997), no Ensino Fundamental, colocou para o estado a condição de transferir recursos do Fundo para seus municípios, em razão da indução à municipalização do Ensino Fundamental que, no estado do Mato Grosso do Sul deu-se curso desde 1993. (FERNANDES, 2001).

A propósito, em 1993, a Secretaria de Estado de Educação municipalizou matrículas do atual Ensino Fundamental a partir de transferências de unidades escolares para os municípios por meio do Programa Descentralização e Fortalecimento do Ensino de Primeiro Grau (FERNANDES, 2001), processo, contudo, diferenciado da municipalização induzida pelo Fundef, à medida que esse transfere matrículas per capita.

Embora a implantação do Programa Descentralização e Fortalecimento do Ensino de Primeiro Grau, em 1998, 56,20\% das matrículas do Ensino Fundamental público, estavam na esfera estadual e $43,8 \%$ estavam na esfera municipal. (INEP, 1999). Em 2006, essa situação se encontrava já totalmente invertida em decorrência da operacionalização do Fundef: $42,62 \%$ das matrículas do Ensino Fundamental público na esfera estadual (INEP, 2007) e $57,38 \%$ estavam na esfera municipal. Houve, também de 1998 a 2006, no estado, uma redução de 55.286 matrículas no Ensino Fundamental público. (INEP, 2007).

No que tange ao Ensino Médio, pontua-se que no estado do Mato Grosso do Sul a população de 15 a 17 anos em 1996 era de 126.147 (IBGE, 2000), e em 2006 era de 144.695 (IBGE/SIDRA, 2006), enquanto que as matrículas oferecidas pela rede estadual de ensino eram respectivamente em 1996 de 57.055, em 1998 de 66.655 (INEP, 1999), e em 2006 de 85.139 (INEP, 2007). Nesse período, a população dessa faixa etária aumentou cerca de $12,8 \%$ no estado e as matrículas na rede estadual de ensino aumentaram $32,9 \%$. (MATO GROSSO DO SUL, 2006a).
De fato, no período que se estendeu de 1998 a 2006, a rede estadual de ensino foi responsável em 1998 por $79 \%$, e em 2006 por $85 \%$ das matrículas do Ensino Médio (BRAZ, 2008, p. 137), atendendo, portanto, a maioria da população nessa etapa da educação básica. Do mesmo modo, outra observação, no período de 1998 a 2006, para o Ensino Médio, foi a alteração de turno frequentado na rede estadual pelo aluno. Enquanto que, em 1998, $71,6 \%$ dos alunos do Ensino Médio frequentavam a escola no período noturno e $28,4 \%$ no período diurno, em $200647,1 \%$ estavam matriculados no noturno e $52,9 \%$ estavam matriculados no diurno. (INEP, 2007).

Não obstante essa alteração de turno, Braz (2008) registrou que parte significativa do aumento de matrículas do Ensino Médio a partir de 1998 se deveu às matrículas do Ensino Médio na modalidade Educação de Jovens e Adultos (EJA), que saltou de 8.518 para 28.868 em 2006. No Ensino Médio regular houve diminuição de 2.493 matriculas de 2004 a 2006. (INEP, 2005; 2007).

Em 2001 também foi implantado pela Secretaria de Estado de Educação, com a denominação de Programa Especial, aquele que ficou conhecido como "Cursinho Popular", um programa destinado a preparar os "jovens do último ano do Ensino Médio e também da modalidade educação de jovens e adultos de baixa renda" (MATO GROSSO DO SUL, 2001a, p. 15) para o vestibular. Esse programa, inicialmente destinado a Campo Grande, em 2006, estava presente em 15 dos 78 municípios do estado, atendendo a 9.833 jovens. O curioso foi que esses jovens não constaram em documentos estatísticos da Secretaria de Estado de Educação, apenas o atendimento foi mencionado em material de divulgação do programa "Cursinho Popular", atualmente Curso Estadual Preparatório para Vestibular (CEPV). (MATO GROSSO DO SUL, 2001b).

Importa considerar o impacto causado pela implantação do Fundef no Ensino Médio no período, pois, conforme Braz (2008), a decisão, por parte da Secretaria de Estado de Educação em rever o convênio com o MEC/BID a partir de 1999, se deveu à constatação de que a operacionalização do Fundo deixou essa etapa da Educação Básica sendo financiada com escassez de recursos.

\section{O impacto da implantação e da operacionali- zação do Fundef no Ensino Médio no estado de Mato Grosso do Sul (1998 a 2006)}

Em estudos anteriores (FERNANDES; TIBANA, 2008a; FERNANDES; D'AVILA, 2008b), constatou-se que o Fundef no estado do Mato Grosso do Sul operou no sentido já observado por Davies (1999, p. 17), 
Além de não garantir nem o desenvolvimento, nem a melhoria do Ensino Fundamental, pela sua lógica de redistribuição dos recursos com base no número de matrículas existentes, o Fundef contribui para enfraquecer e desarticular o sistema de ensino, uma vez que, segundo a Lei 9.424, as matrículas da educação infantil, de jovens e adultos (supletivo) e do ensino médio não são consideradas para efeitos de redistribuição dos recursos.

Não obstante essa situação, importa considerar que, até a implantação do Fundef, era impossível depurar os gastos com manutenção e desenvolvimento do ensino (MDE), ${ }^{1}$ para o Ensino Médio no estado, principalmente considerando como fonte primária os Balanços Anuais de Contas de Governo. De fato, nesses documentos, até 1998, sempre as despesas com MDE ocorriam por parte de toda a Educação Básica sem discriminação de etapas ou modalidades, quando se apresentavam como contas únicas programáticas.

Nesse sentido, não se pode negar a transparência da aplicação dos recursos em MDE por estados e municípios, organizado pela operação contábil do Fundef. Os recursos para MDE, contudo, continuaram os mesmos, ou seja, aqueles advindos da vinculação constitucional de recursos (Artigo 212 da Constituição Federal). (BRASIL, 1988).

Destaca-se que o Fundef foi instituído pela Emenda Constitucional $\mathrm{n}^{\circ}$. 14, de setembro de 1996 (BRASIL, 1996b), e regulamentado pela lei $n^{\circ}$. 9.424, de 24 de dezembro do mesmo ano. (BRASIL, 1996a). O Fundo foi implantado, nacionalmente, em primeiro de janeiro de 1998, e passou a instituir uma nova sistemática de redistribuição dos recursos destinados à Educação Básica.

Assim, o Fundef operou aplicando $15 \%$ de recursos estaduais e municipais dos seguintes impostos: Impostos sobre Circulação de Mercadorias e Serviços (ICMS), Fundo de Participação dos Estados (FPE), Fundo de Participação dos Municípios (FPM) e Impostos sobre Produtos Industrializados (IPI).

Tal lógica instituída pela política de fundos evidenciou que os entes subnacionais - estados e municípios -, ao disporem de $25 \%$ das receitas de impostos para financiar a MDE, redistribuíram os $10 \%$ restantes na primeira etapa (Educação Infantil) ou na última etapa (Ensino Médio) da Educação Básica - de acordo com o regime de colaboração

\footnotetext{
Conforme estabeleceu o Artigo 212 da Constituição Federal (BRASIL, 1988): A União deve aplicar, anualmente, nunca menos de $18 \%$, e os estados, o Distrito Federal e os municípios, $25 \%$, no mínimo, da receita resultante de impostos, compreendida a proveniente de transferências, na manutenção e desenvolvimento do ensino.
}

instituído. No caso do Mato Grosso do Sul, também no Ensino Superior, para financiar a Universidade Estadual de Mato Grosso do Sul (UEMS). Diante dessa operação, à medida que se aumentaram os recursos de uma etapa do ensino, consequentemente foram diminuídos para as outras; pois o que se alterou foi a distribuição do percentual para financiar a MDE, não o montante total de recursos, que é sempre dado pelo dispositivo constitucional dos $25 \%$ da receita resultante de impostos. Situação essa que corrobora para assimetrias, pois, como o que financia a MDE é o percentual da receita de impostos, quanto mais um estado ou município arrecada, mais recurso terá para financiar a MDE. Tal situação concorre para que os estados e os municípios industrializados tenham um maior aporte de recursos em razão direta do modelo tributário brasileiro instituído, processo que reforça as desigualdades regionais.

Há que se registrar, contudo, dois movimentos importantes em relação às decisões tomadas por parte do Poder Executivo, ambas com aprovação do Poder Legislativo, que antecederam à implantação do Fundef e que impactaram a política educacional do estado. Essas decisões explicaram o movimento e o valor das contas da Secretaria de Estado de Educação a partir de então. O primeiro movimento atendeu a um dos objetivos do Fundef que foi a municipalização do Ensino Fundamental. O segundo movimento foi a aprovação da Emenda Constitucional Estadual $n^{\circ}$. 6, de 02 de julho de 1997 (MATO GROSSO DO SUL, 1997a), que reduziu de $30 \%$ para $25 \%$ os recursos vinculados constitucionalmente para a MDE (FERNANDES, 2003), situação que explicou a redução dos recursos nos programas da Secretaria de Estado de Educação entre os anos de 1996 e 1997. Observou-se entre esses anos, uma redução da ordem de 27,19\% dos recursos para a MDE no estado como pode se identificar na tabela $1 \mathrm{~A}$.

Assim as tabelas $1 \mathrm{~A}$ e $1 \mathrm{~B}$ apresentam os recursos constitucionais para financiar a MDE no estado, a partir de 1996, quando pode se verificar o impacto, tanto da aprovação da Emenda Constitucional Estadual n. 6/1997 (MATO GROSSO DO SUL, 1997a), quanto da implantação do Fundef em 1998. Também se observa nas tabelas mencionadas o comportamento desses recursos durante as duas administrações consecutivas do Poder Executivo estadual sob a hegemonia do PT, que foi de 1999 a 2006. 
A convivência entre o Programa Escola Guaicuru - Vivendo Uma Nova Lição e o Programa... 225

Tabela $1 \mathrm{~A}^{2}$ - Secretaria de Estado de Educação de Mato Grosso do Sul: despesas realizadas por programas e função (1996 a 2000)

\begin{tabular}{|c|c|c|c|c|c|}
\hline Programa & $\begin{array}{l}1996 \\
(\mathrm{R} \$)\end{array}$ & $\begin{array}{l}1997 \\
(\mathrm{R} \$)\end{array}$ & $\begin{array}{l}1998 \\
(\mathrm{R} \$)\end{array}$ & $\begin{array}{l}1999 \\
(\mathrm{R} \$)\end{array}$ & $\begin{array}{c}2000 \\
(R \$)\end{array}$ \\
\hline Administração & $182.722 .039,68$ & $137.727 .247,60$ & $135.919 .719,43$ & $56.645 .116,96$ & $85.338 .236,43$ \\
\hline Adm. financeira & $11.563 .497,29$ & $2.632 .360,94$ & $1.041 .452,96$ & $3.364 .625,74$ & - \\
\hline Telecomunicações & $2.650 .804,44$ & $2.919 .637,72$ & $3.455 .077,92$ & $5.515 .789,48$ & - \\
\hline Crianças de 0 a 6 anos & $3.883 .481,06$ & $2.727 .836,83$ & $3.049 .376,81$ & - & \\
\hline Ensino Fundamental & $2.385 .936,33$ & $1.101 .131,41$ & $120.571 .273,07$ & $248.198 .423,59$ & $309.711 .831,89$ \\
\hline Ensino Médio & - & - & $1.091 .070,78$ & $127.857,60$ & $628.731,81$ \\
\hline Ensino Superior & 7.891.341,02 & $6.913 .001,05$ & $7.974 .601,56$ & $8.079 .049,33$ & $11.411 .982,75$ \\
\hline Ed. Física e Desportos & $627.975,59$ & $71.418,59$ & $1.117 .773,21$ & $824.433,15$ & - \\
\hline $\begin{array}{c}\text { Assistência a } \\
\text { educandos }\end{array}$ & 2.385.936,33 & $1.101 .131,41$ & - & - & - \\
\hline Cultura & $1.298 .978,21$ & $1.300 .726,06$ & $2.071 .459,38$ & $1.615 .738,26$ & - \\
\hline Assistência & $4.238 .245,52$ & $2.136 .061,71$ & $2.833 .162,28$ & $3.775 .027,03$ & - \\
\hline Total função educação & 217.262.299,14 & $158.171 .421,91$ & $279.124 .967,80$ & $328.146 .061,14$ & $457.218 .520,64$ \\
\hline
\end{tabular}

Fonte: MATO GROSSO DO SUL: Balanço Anual de Contas de Governo dos anos: 1996, 1997b, 1998, 1999b e 2000a.

Tabela 1B $\mathrm{B}^{3}$ - Secretaria de Estado de Educação de Mato Grosso do Sul: despesas realizadas por programas e função (2001 a 2006)

\begin{tabular}{|c|c|c|c|c|c|c|}
\hline Programa & $\begin{array}{l}2001 \\
(\mathrm{R} \$) \\
\end{array}$ & $\begin{array}{l}2002 \\
(\mathrm{R} \$)\end{array}$ & $\begin{array}{l}2003 \\
(\mathrm{R} \$)\end{array}$ & $\begin{array}{c}2004 \\
(\mathrm{R} \$)\end{array}$ & $\begin{array}{c}2005 \\
(\mathrm{R} \$)\end{array}$ & $\begin{array}{l}2006 \\
(\mathrm{R} \$)\end{array}$ \\
\hline $\begin{array}{l}\text { Administração } \\
\text { Geral }\end{array}$ & $116.266 .859,51$ & $108.523 .562,25$ & $121.766 .104,57$ & - & - & - \\
\hline $\begin{array}{c}\text { Ensino } \\
\text { Fundamental }\end{array}$ & $333.709 .183,45$ & $200.895 .186,31$ & $235.937 .693,16$ & $430.594 .616,28$ & $396.078 .833,44$ & $446.760 .457,18$ \\
\hline Ensino Médio & $3.541 .680,59$ & $3.045 .442,47$ & $3.228 .350,41$ & $38.049 .939,27$ & $39.037 .839,79$ & $63.154 .544,34$ \\
\hline $\begin{array}{c}\text { Ensino } \\
\text { Profissional }\end{array}$ & $203.411,29$ & $2.097 .752,57$ & $977.866,25$ & $871.559,13$ & $884.287,63$ & $778.408,23$ \\
\hline Ensino Superior & $14.650 .291,42$ & $18.880 .851,89$ & $25.422 .985,02$ & $29.565 .190,35$ & $35.040 .878,29$ & $41.429 .954,39$ \\
\hline EJA & $415.657,50$ & $276.617,28$ & $2.953 .098,20$ & $2.003 .021,15$ & $7.631 .631,05$ & $12.718 .262,35$ \\
\hline $\begin{array}{c}\text { Educação } \\
\text { especial }\end{array}$ & $47.809,01$ & $162.813,32$ & $88.838,05$ & $521.080,06$ & $730.865,48$ & $930.339,79$ \\
\hline $\begin{array}{l}\text { Difusão conh. } \\
\text { Cient. e Tec. }\end{array}$ & $344.830,68$ & $570.725,43$ & $2.119 .202,21$ & $2.029 .364,74$ & $2.721 .602,94$ & $2.809 .294,63$ \\
\hline $\begin{array}{l}\text { Total função } \\
\text { educação }\end{array}$ & $469.179 .723,45$ & $334.452 .951,52$ & $392.494 .137,87$ & $503.634 .770,98$ & $500.125 .938,62$ & $568.581 .260,91$ \\
\hline
\end{tabular}

Fonte: MATO GROSSO DO SUL: Balanço Anual de Contas de Governo dos anos: 2001c, 2002, 2003, 2004, 2005 e $2006 \mathrm{~b}$.

\footnotetext{
${ }^{2}$ Constituem-se nas despesas com manutenção e desenvolvimento do ensino (MDE), ou recursos vinculados constitucionalmente para MDE, conforme dispôs o Artigo 212 da Constituição Federal de 1988 (BRASIL, 1988). No estado de Mato Grosso do Sul os recursos para MDE foram dispostos pelo Artigo 198 da Constituição Estadual de 1989, (MATO GROSSO DO SUL, 2006c), sendo que este Artigo foi alterado pela Emenda à Constituição Estadual de no 6, de 02 de julho de 1997. (MATO GROSSO DO SUL, 1997a). Esta disposição constitucional encontra-se normatizada pelos Artigos 70 e 71 da Lei de Diretrizes e Bases da Educação Nacional - Lei n $9.394 / 1996$. (BRASIL, 1996).

${ }^{3}$ Refere-se aos mesmos dispositivos legais citados na nota 2.
}

Práxis Educativa, Ponta Grossa, v.5, n.2, p. 221-232, jul.-dez. 2010. Disponível em <http://www.periodicos.uepg.br> 
Pontua-se que, com a implantação do Fundef o

[...] poder público ficou obrigado, na questão do gasto, a dar prioridade ao Ensino Fundamental [...], com a intenção de: aperfeiçoar o processo de gerenciamento orçamentário e financeiro; garantir aumento de recursos [...]; dar visibilidade à gestão dos recursos e valorizar o magistério. (CASTRO, 1998, p. 8-9).

No caso do estado do Mato Grosso do Sul, observou-se que, dessas premissas elencadas por Castro (1998), positivamente houve o processo de aperfeiçoamento de gerência orçamentária e financeira e visibilidade dos recursos. Quanto a aumentos de recursos, como já mencionado, a unidade federada se preveniu por meio de medidas legais diminuindo dispêndios para MDE.

Assim pode-se observar que, a partir do balanço de 2001, incluiu-se no Programa Ensino Fundamental, a conta Gestão da Dívida Pública. Tal organização contábil foi possível em razão da aprovação da Lei n. 2.261, de 16 de julho de 2001 (MATO GROSSO DO SUL, 2001d), denominada Lei do Rateio. Essa Lei normatizou entre os órgãos do Poder Executivo a divisão de despesas de consumo e, na prática, estabeleceu que quem tinha recursos pagava as contas daqueles que não os possuíam. Assim, a Secretaria de Estado de Educação de 2001 a 2006 deixou de aplicar na MDE R\$ 619.067.548,19 (BRAZ, 2008, p. 193) para atender a Lei do Rateio.

Além disso, embora a criação da Universidade Estadual de Mato Grosso do Sul (UEMS), estivesse disposta no Artigo 48, nos Atos das Disposições Constitucionais Gerais e Transitórias (ADCGT) da Constituição Estadual de 1989 (MATO GROSSO DO SUL, 2006), cuja tarefa foi cumprida em 1992, essa instituição vem sendo mantida desde então com recursos da Educação Básica, como mostraram as tabelas $1 \mathrm{~A}$ e $1 \mathrm{~B}$.

Da mesma forma, Braz (2008, p. 194) afirmou que migraram recursos de MDE, de 2001 a 2005, para o Fundo de Investimento Social (FIS) e também cerca de $\mathrm{R} \$ 1,5$ milhão em verbas para MDE entre 1999 a 2002 foram aplicados no programa Bolsa Escola, atendendo a 946 famílias com vistas à universalização do Ensino Fundamental.

Obviamente que tais dispêndios financeiros não se constituíram em MDE como determinado pela Lei $n^{\circ}$. 9.394/1996, o que demonstrou no período a condição de o estado do Mato Grosso do Sul ser considerado como um infiel depositário do erário público, à medida que não primou pelos recursos vinculados constitucionalmente para MDE.

Assim, diante da aplicação de recursos para MDE pelo estado, constatou-se que a prioridade foi de fato o Ensino Fundamental. Não obstante, o Ensino Médio durante o período ter tido oscilações na aplicação de recursos para MDE como se constatou nas tabelas $1 \mathrm{~A}$ e $1 \mathrm{~B}$.

Foi o contexto, portanto, do financiamento com escassez de recursos para o Ensino Médio que ensejou a razão de Estado para a Secretaria Estadual de Educação justificar a retomada, em 2000, do Programa Melhoria e Expansão do Ensino Médio (Promed/Escola Jovem).

\section{A implantação e a operacionalização do Pro- grama Melhoria e Expansão do Ensino Mé- dio (Promed/Escola Jovem) no estado do Mato Grosso do Sul}

Durante a gestão do Governador Wilson Barbosa Martins (1994 a 1998), cuja proposta para a política educacional era informada pelo programa A Cidadania Começa na Escola, (MATO GROSSO DO SUL, 1996), houve a adesão da Secretaria de Estado de Educação ao Contrato de Empréstimo ${ }^{\circ}$. 1052/OC-BR, que foi firmado em 24 de novembro de 1997, pela República Federativa do Brasil e o Banco Interamericano de Desenvolvimento, dando inicio pelo MEC, ao Programa Melhoria da Educação Profissional (PROEP), que "incluiu dois subprogramas: o de Implantação de Políticas Globais, que tinha como finalidade equipar o MEC e o de Planos Estaduais e Projetos Escolares que tinha como finalidade executar investimentos dos estados e das escolas participantes no programa" (BRAZ, 2008, p. 213). Eis as raízes do Programa Melhoria e Expansão do Ensino Médio (Promed/Escola Jovem), que tinha como objetivo, segundo o MEC:

[...] a ampliação do grau de cobertura do ensino médio, atendendo, em particular, aos jovens em idade escolar; reduzir os índices de reprovação e de abandono nessa etapa da escolaridade e garantir que os alunos adquiram as competências e habilidades necessárias ao exercício da cidadania e à participação no mundo do trabalho. O desenvolvimento das ações implementadas pelo Projeto Escola Jovem tem propiciado um notável desenvolvimento socioeconômico aos Estados, contribuindo para diminuir o índice de evasão escolar, fortalecendo as instituições, capacitando os docentes, melhorando a qualidade do ensino, reordenando e expandindo a rede física. (BRASIL, 2001, p. 2).

Diante disso, as verbas dos convênios firmados eram transferidas pelo MEC aos estados, que, em contrapartida, deveriam aplicar recursos de suas próprias fontes. O montante de recursos transferido via convênio era calculado para o repasse ao estado de acordo com as matrículas no Ensino Médio e também com a eficácia do sistema educacional estadual ao atendimento do Ensino Fundamental. (BRASIL, 2001).

Com o propósito de reformar e expandir o Ensino Médio, a Secretaria de Estado de Educação 
A convivência entre o Programa Escola Guaicuru - Vivendo Uma Nova Lição e o Programa...

elaborou seu plano de trabalho, apresentando como diretrizes: fortalecimento institucional, qualidade social, comunicação e difusão, democratização do acesso, desenvolvimento curricular e racionalização e expansão da rede escolar e melhoria do atendimento. (MATO GROSSO DO SUL, 2000b, p. 4).

Para a implantação dessas diretrizes, o plano de trabalho da Secretaria de Estado de Educação elaborou um orçamento da ordem de R\$ 9.571.615,74.

Depois da análise do plano de trabalho da Secretaria de Estado de Educação pelo MEC, o valor solicitado foi reduzido na ordem de $24,2 \%$, cujo valor ficou em $\mathrm{R} \$ 7.257 .979,00$. Assim, a parceira BID/MEC aplicou R\$3.824.456,00, e coube ao estado aplicar R\$3.433.523,00. (BRAZ, 2008).

Esses valores mostraram que o estado aplicou $47,3 \%$ de recursos para a expansão do Ensino Médio, e não $50 \%$ como normatizava o contrato firmado com o BID/MEC. Essa situação demonstrou o não cumprimento por parte do estado das normas estabelecidas pelo convênio.

Em 2000, a Secretaria de Estado de Educação novamente recorreu ao MEC que deferiu seu Plano de
Trabalho, mas o estado não conseguiu cumprir os prazos estabelecidos pelo convênio porque não efetivou os empenhos dos recursos em tempo hábil, inviabilizando a aplicação das verbas do convênio. Situação que levou o estado mais uma vez a solicitar prorrogação de prazo para cumprimento das metas do Programa. Como argumentou Braz (2004, p. 156):

\begin{abstract}
Um outro componente dificulta, encarece e retarda a execução das ações, qual seja, a morosidade própria da Secretaria do Estado, que muitas vezes inviabiliza o gasto do dinheiro. O prazo de licitação ou de aprovação de termos aditivos, por exemplo, leva em torno de 8 a 9 meses e de 3 a 4, respectivamente, fazendo com que muitas vezes, o dinheiro precise ser devolvido ao MEC, pelo não cumprimento dos prazos planejados para seu uso [...] a proposta curricular que elaborada dentro das exigências do PEM em 2002 só agora, em meados de 2004, foi publicada para ser distribuída às escolas.
\end{abstract}

A Tabela 2 ilustra a distribuição dos recursos do Programa Melhoria e Expansão do Ensino Médio (Promed/Escola Jovem) em sua primeira fase, no ano de 2000.

Tabela 2 - Recursos do Programa Melhoria e Expansão do Ensino Médio (Promed/Escola Jovem) para o estado do Mato Grosso do Sul (2000)

\begin{tabular}{c|c|c}
\hline \multirow{2}{*}{$\begin{array}{c}\text { Categoria Econômica de } \\
\text { Despesas }\end{array}$} & \multicolumn{2}{|c}{ Valores aplicados } \\
\cline { 2 - 3 } & $\mathbf{R} \mathbf{\%}$ & $\mathbf{\%}$ \\
\hline Infraestrutura Física & 0,00 & 0,00 \\
\hline Equipamento e mobiliário & $1.160 .710,00$ & 15,99 \\
\hline Capacitação & $5.044 .469,00$ & 69,50 \\
\hline Materiais Didáticos & $125.200,00$ & 1,72 \\
\hline Consultoria & $44.000,00$ & 0,62 \\
\hline Outros Serviços & $883.600,00$ & 12,17 \\
\hline Total & $\mathbf{7 . 2 5 7 . 9 7 9 , 0 0}$ & $\mathbf{1 0 0}$ \\
\hline
\end{tabular}

Fonte: BRASIL, 2000. Dados extraídos do Parecer 016/00 - MEC

A operacionalização do Programa Melhoria e Expansão do Ensino Médio (Promed/Escola Jovem), seguiu a tônica por todo o período aqui apresentado de o estado não conseguir organizar em tempo hábil sua contabilidade para cumprir sua parte das normas expressas em contrato.

Pontua-se que a Secretaria de Estado de Educação no período de 1999 a 2006 foi administrada por quatro Secretários. Essa constante mudança no comando da pasta foi, possivelmente, a razão do pedido de nove Termos Aditivos ${ }^{4}$ ao Convênio, situa-

\footnotetext{
${ }_{4}$ Assinados até o ano de 2005, reprogramando o tempo de aplicação dos recursos financeiros, com prazo até julho de 2006, para encerramento e cumprimento das metas. (BRAZ, 2008, p. 221).
}

ção que sempre retardava a aplicação dos recursos no Ensino Médio.

Na segunda gestão do executivo estadual sob hegemonia do Partido dos Trabalhadores (PT), de 2002 a 2006, assumiu a Secretaria de Estado de Educação o professor Hélio de Lima. Nessa gestão, a primeira ação realizada em relação ao andamento do Programa Melhoria e Expansão do Ensino Médio (Promed/Escola Jovem) foi a devolução de $R \$ 43.976,90$, por não tais recursos não terem sido aplicados no tempo devido. A explicação dada para esse fato seria a necessidade de estudar e compreender as ações executadas pelas gestões anteriores, permitindo uma adequação aos objetivos do governo em seu novo mandato. 
Para se ter ideia do montante de recursos devolvidos para o convênio em âmbito federal, apresenta-se a Tabela 3, que demonstra a parte de recursos não aplicados pelo estado como sua con- trapartida, contas essas denominadas pelo Estado de "devoluções", ou como argumentou Braz (2008), de perdas de recursos para a Educação, em especial para o Ensino Médio.

Tabela 3 - Resumo dos recursos do Programa Melhoria e Expansão do Ensino Médio (Promed/ Escola Jovem) e dos recursos da fonte estadual

\begin{tabular}{l|c|c|c|c}
\hline \multicolumn{2}{c|}{ Recursos } & Despesas & Devolução & Não aplicação \\
\hline BID MEC & $\mathrm{R} \$ 4.951 .341,52$ & $\mathrm{R} \$ 4.177 .428,67$ & $\mathrm{R} \$ 773.912,95$ & $\mathrm{R} \$ 249.634,68$ \\
Estado & $\mathrm{R} \$ 4.520 .487,00$ & $\mathrm{R} \$ 3.833 .746,04$ & & $\mathrm{R} \$ 689.740,96$ \\
\hline Total & $\mathrm{R} \$ 9.471 .828,52$ & $\mathrm{R} \$ 8.011 .174,71$ & $\mathrm{R} \$ 773.912,95$ & $\mathrm{R} \$ 934.875,64$ \\
\hline
\end{tabular}

Fonte: Tabela elaborada por D'Avila, J. L. a partir do trabalho de Braz, T. (2008).

Ainda assim em 2004, a Secretaria de Estado de Educação realizou um novo convênio com o BID/
MEC num total de $\mathrm{R} \$ 2.305 .490,00$, que foram investidos nas metas apresentadas na Tabela 4:

Tabela 4 - Convênio 025/2004/BID/MEC/ MS - Plano de aplicação

\begin{tabular}{l|c|c}
\hline \multicolumn{1}{c|}{ METAS } & BID/MEC & ESTADO \\
\hline $\begin{array}{l}\text { 1 - Valorização dos Profissionais da Educação } \\
1.1 \text { Capacitação dos docentes, coordenadores pedagógicos e } \\
\text { assessores técnicos para o Ensino Médio Noturno e Educação } \\
\text { de Jovens e Adultos, etapa Ensino Médio - EJA }\end{array}$ & $\mathrm{R} \$ 459.260,00$ & \\
\hline $\begin{array}{l}\text { 2 - Racionalização e expansão da rede escolar e melhoria } \\
\text { de atendimento. }\end{array}$ & $\mathrm{R} \$ 180.900,00$ & $\mathrm{R} \$ 180.900,00$ \\
$\begin{array}{l}\text { 2.1 Ampliação e reforma de 18 quadras poliesportivas; } \\
\text { es Aquisição de acervo bibliográfico para 270 escolas da rede } \\
\text { escolar do Estado; }\end{array}$ & & \\
2.3 Aquisição de material didático-pedagógico. & $\mathrm{R} \$ 341.330,00$ & \\
\hline TOTAL & $\mathrm{R} \$ \mathbf{9 8 1 . 4 9 0 , 0 0}$ & $\mathbf{R} \$ \mathbf{1 . 3 2 4 . 0 0 0 , 0 0}$ \\
\hline
\end{tabular}

Fonte: BRASIL, 2004. Convênio 025/2004/MEC/BID/MS.

Como pode se observar na Tabela 4 , a Secretaria de Estado de Educação investiu grande parte dos recursos na meta denominada "Racionalização e expansão da rede escolar e melhoria de atendimento". Cabe considerar que, o Ensino Médio no estado historicamente vem sendo ofertado na mesma rede física que o Ensino Fundamental. De fato, a mesma escola que tem atendido o aluno do Ensino Fundamental, atende também o aluno do Ensino Médio, com exceção de uma escola situada no município de Campo Grande que exclusivamente atende os alunos do Ensino Médio.

Assim a ação 2.1 - ampliação e reforma de 18 quadras poliesportivas - que recebeu um investimento da ordem de $\mathrm{R} \$ 1.504 .900,00$, esteve de acordo com o histórico de atendimento da rede estadual que tem sido o de atender as matrículas do Ensino Fundamental e do Médio no mesmo espaço físico. (FERNANDES, 2000).

Em relação à ação 2.3 - aquisição de material pedagógico - constatou-se que parte dos recursos investidos nessa ação deveu-se a elaboração dos Referenciais Curriculares para o Ensino Médio. Pontua-se que os referenciais curriculares da rede estadual tanto para o Ensino Médio quanto para o Ensino Fundamental, vinham sendo discutidos no bojo do Movimento Constituinte Escolar. Esse Movimento foi um processo desencadeado pela Secretaria de Estado de Educação em 1999, com o objetivo de "construir coletivamente com a rede estadual de ensino e a sociedade sul mato-grossense o Plano Estadual de Educação". (PERONI, 2004, p. 57). Esse processo foi interrompido em 2001, por ocasião da exoneração do secretário de estado de Educação, professor Pedro Cesar Gonçalves Kemp, pelo governador José Orcírio Miranda dos Santos.

Nessa conjuntura, apesar do compromisso do governo do estado com a continuidade do Movimento Constituinte Escolar - uma vez que seu secretário de governo alegara que tal Movimento era um projeto estruturante do planejamento estadual (MATO GROSSO DO SUL, 2001e, p. 01) -, o secretário de 
A convivência entre o Programa Escola Guaicuru - Vivendo Uma Nova Lição e o Programa...

estado de Educação que assumiu em setembro de 2001, professor Antonio Carlos Biffi, tinha outras prioridades para a política educacional. Entre essas prioridades, encontrava-se a adesão total à política educacional em curso pelo Governo Federal, situação que levou à obsolescência a critica radical inicialmente realizada pela Secretaria Estadual de Educação - em seus documentos aqui já citados aos princípios do neoliberalismo que pautavam o projeto educacional da União.

Não obstante, o executivo estadual decidiu, no ano de 2005 , reduzir em $44,33 \%$ os valores do convênio firmado com o BID/MEC, ou seja, dos R\$ $7.257 .979,00$ iniciais passou para $R \$ 4.041 .504,00$. Essa medida, segundo a Coordenadoria do Ensino Médio da Secretaria de Estado de Educação, foi necessária, pois, havia muitas metas a serem cumpridas e a lentidão nos processos licitatórios não permitiu ao estado aplicar os $100 \%$ da contrapartida.

A devolução de recursos, porém, se fez presente também em 2006: a Secretaria de Estado de Educação, por não conseguir cumprir mais uma vez com as metas do Programa, devolveu o valor R\$ 25.164,11 para o MEC. A Secretaria de Estado de Educação alegou que os motivos para essa prática foram inúmeros, alegando a

[...] falta de previsão dos recursos no Orçamento do MS; dificuldades de liberação dos recursos da contrapartida do Estado, no momento em que esses eram solicitados; variação no valor do dólar, exigindo a reprogramação dos valores das aplicações; burocracia a ser obedecida para a aplicação dos recursos; morosidade nas licitações realizadas pela Secretaria de Fazenda do Mato Grosso do Sul; lentidão dos técnicos da SED no planejamento da aplicação; dificuldade dos técnicos da SED em atender às exigências e prestar contas do dinheiro gasto ao MEC; as trocas periódicas das equipes técnicas da SED, por ocasião de mudanças de secretários estaduais e ministros; e o tempo levado para que cada Termo Aditivo chegasse a ser aprovado e publicado. (BRAZ, 2008, p. 221).

Destaca-se que os investimentos realizados pelo Banco Mundial, na verdade, são empréstimos com juros elevados, que contribuem para aumentar a dívida externa do País. Rodrigues (2006) esclarece que, os investimentos destinados às políticas educacionais, seguem as mesmas regras de qualquer outro projeto econômico, financiado pelas agências internacionais, o que implica no aumento de encargos, ou seja, de juros e ajustes cambiais, quando ocorre atraso na execução dos programas.

O BID, desde sua fundação, já participou de aproximadamente 175 projetos brasileiros. Somente no ano de 1997 foram emprestados ao Brasil cerca de US\$ 2 bilhões. Essas cifras parecem ser elevadas, porém se compararmos com o orçamento da União no mesmo período, esses US\$ 2 bilhões corresponderam a $1 \%$ do orçamento que foi encaminhado para o Congresso Nacional. (VIANNA, 1998). Ressalta o autor que os Bancos Multilaterais de Desenvolvimento, como o BID, são mais importantes na orientação "como inteligência", atuando como auxiliares de governos na elaboração de programas e projetos, do que exercendo uma função meramente financeira.

Tanto é assim que em um dos estudos elaborados pelo Banco Mundial, em parceria com o Governo do Brasil, encontra-se o "Educação secundária no Brasil: chegou a hora". Nessa obra, os autores salientaram que o financiamento do Ensino Médio deveria dar conta da "expansão do acesso à escola e a melhoria da qualidade escolar". (RODRÍGUEZ; HÉRRAN, 2000, p. 97). E ainda que,

[...] a redução dos índices de repetência e desistência, a expansão do acesso para estudantes em áreas de cobertura difícil (inclusive a rural), a meIhoria da qualidade e da relevância do ensino (particularmente na escola noturna, que provavelmente serve os segmentos mais pobres da população). (RODRÍGUEZ; HÉRRAN, 2000, p. 97).

Pode-se argumentar que as metas citadas são nobres e necessárias, porém, o mais interessante é que o Banco exime o Governo Federal da sua participação do financiamento do Ensino Médio, negando sua tarefa supletiva, paradoxalmente, a razão que alegam os governos estaduais para aderirem, no campo educacional, aos convênios encetados pelo MEC. Assim o Banco reconhece que: "[...] Embora a assistência federal seja importante, o maior peso desses desafios recairá diretamente sobre os estados. [...] Estes desafios devem ser atacados agora e já". (RODRÍGUEZ; HÉRRAN, 2000, p. 97).

$\mathrm{Na}$ singularidade sul mato-grossense, os recursos que foram utilizados no ensino, oriundos das fontes internacionais, ampliaram a dívida do estado para com o governo central. Paradoxalmente, foram os recursos do Programa Melhoria e Expansão do Ensino Médio (Promed/Escola Jovem) que possibilitaram ao estado:

[...] a investir no Ensino Médio para além da folha de pagamento. Para o trabalho da SED foi um recurso muito significativo, porque os recursos antes disponibilizados eram ínfimos e não possibilitavam o desenvolvimento de ações pedagógicas, encontros ou debates sobre a qualidade do Ensino Médio. No entanto, a efetividade de seus resultados em relação aos objetivos propostos é questionável, porque, conforme já se mencionou, as ações não foram contínuas, não houve acompanhamento, assim como não houve e não foi programado financiamento para a escola executar o Referencial Curricular proposto. Dessa forma, o PROMED/Escola Jovem mostrou-se dispendioso do ponto de vista de se ampliar a dívida do estado e pouco relevante do ponto de vista de seus resultados educacionais. 
O montante de recursos seria plenamente coberto se o estado de MS cumprisse o mínimo estabelecido na Constituição Federal, art. 212. Ganharia, assim, liberdade de planejar suas ações conforme suas reais necessidades para alcançar a universalização do Ensino Médio com qualidade. (BRAZ, 2008, p. 232).

Aqui se volta à questão central: quando analisados os empréstimos do BID, por meio do Programa Expansão e Melhoria do Ensino Médio (Promed/ Escola Jovem), confirmou-se que não houve uma instrumentalização de todas as escolas e que as metas como as de capacitação para professores, entre outras, não foram realizadas. Segundo Braz (2008), os recursos do Programa Expansão e Melhoria do Ensino Médio (Promed/Escola Jovem) foram insuficientes para se alcançar uma excelência em Educação, e a autora afirma ainda que "os recursos são tão gotejados" que obrigaram as escolas a elaborar estratégias para a arrecadação de verbas junto à população escolar.

\section{Considerações finais}

Desvelou-se neste trabalho a convivência entre o Programa Escola Guaicuru - Vivendo Uma Nova Lição e o Programa Melhoria e Expansão do Ensino Médio (Promed/Escola Jovem), cujas orientações para a política educacional no período de 1999 a 2006, no estado do Mato Grosso do Sul, teriam raízes ideológicas distintas.

Em termos de concepção de política educacional, o Programa Escola Guaicuru se propunha a ser aquele que reverteria a política educacional neoliberal encetada pelo Governo Federal para o setor, e que, portanto, se manifestaria em um programa com a natureza e os objetivos do Programa Melhoria e Expansão do Ensino Médio (Promed/Escola Jovem).

O exercício da política educacional para o Ensino Médio pelo estado no período, consoante à materialização da reforma educacional empreendida pelo Governo Federal, e a vontade expressada pelo governo estadual no campo do financiamento, foi determinante para que essa etapa da Educação Básica continuasse se efetivando como "o primo pobre da educação brasileira”. (PINTO, 2002).

Ainda duas observações foram importantes para desvelar o convívio entre concepções ditas distintas de políticas educacionais: a primeira seria que o estado, embora se propusesse a reverter o histórico processo de exclusão no Ensino Médio por meio de sua democratização, reproduziu historicamente tal exclusão por meio do financiamento para MDE para essa etapa da Educação Básica; a segunda foi que a morosidade do estado em operar com os recursos do Programa Melhoria e Expansão do Ensino Médio (Promed/Escola Jovem) reforçou o discurso conservador - presente no neoliberalismo de que o Estado é incompetente e ineficaz para gerir recursos.

Foi assim que as ações concretas que se puderam observar em relação à implantação e operacionalização do Programa Melhoria e Expansão do Ensino Médio (Promed/Escola Jovem) no estado do Mato Grosso do Sul, no período de 1999 a 2006, se restringiram a aportes financeiros para construções e reformas de quadras de esporte nas escolas e a publicação, em 2004, dos referenciais curriculares para o Ensino Médio, composto por três volumes.

De fato, cabe lembrar com Fonseca (2003, p. 315), que:

Além dos prejuízos financeiros, merece atenção o fato de que os poucos ganhos que podem ser atribuídos aos projetos internacionais não duram mais que o tempo de execução desses projetos, especialmente quando ocorre cancelamento de crédito e o projeto deve encerrar-se prematuramente, conforme já ocorreu com três acordos entre o Brasil e o BIRD para a educação básica. Estas evidências ilustram o caráter transitório e fugaz da cooperação internacional, no que diz respeito às ações educacionais propriamente ditas. O mesmo não se aplica à questão do financiamento: ao ser encerrada a execução de um determinado projeto, o processo de pagamento da dívida continua em exercício por vários anos. O primeiro acordo MEC/BIRD para a educação técnica, cujas ações foram encerradas em 1978, encontra-se ainda em fase de exercício financeiro, isto é, o país continuará pagando juros e taxas até o ano de 2004, conforme cláusulas fixadas no acordo inicial. Embora esses fatos não sejam conhecidos pela comunidade.

Cabe por último destacar que, no estado do Mato Grosso do Sul, o Ensino Médio, de 1999 a 2006, reproduziu a média nacional em termos de acesso à escola por meio de matrículas. Assim, o estado chegou em 2006, conforme dados do IBGE (2006) e do INEP (2007), no qual, em cada grupo de 100 jovens na faixa etária adequada, apenas 36 deles estão matriculados no Ensino Médio.

\section{Referências}

ABRUCIO, F. L. A dinâmica Federativa da educação brasileira: diagnóstico e propostas de aperfeiçoamento. In: OLIVEIRA, R. P. de.; SANTANA,W. (Orgs.). Educação e federalismo no Brasil: combater as desigualdades, garantir a diversidade. Brasília: UNESCO, 2010, p. 39-70.

BRASIL. Constituição da República Federativa do Brasil. Brasília: Senado Federal, 1988. 
A convivência entre o Programa Escola Guaicuru - Vivendo Uma Nova Lição e o Programa... 231

Lei n. 9.424/1996, de 24 de dezembro de 1996. Dispõe sobre o Fundo de Manutenção e Desenvolvimento do Ensino Fundamental e de Valorização do Magistério Fundef. Diário Oficial da União, Brasília: 26 dez. 1996a.

Emenda Constitucional n. 14/1996, de 12 de setembro de 1996. Modifica os arts. 34, 208, 211 e 212 da Constituição Federal e dá nova redação ao art. 60 do Ato de disposições constitucionais transitórias. Diário Oficial da União, Brasília: 13 set. 1996b.

Lei de Diretrizes e Bases da Educação Nacional n. 9.394, de 1996. Liderança do Partido dos Trabalhadores no Senado Federal. Brasília: Senado Federal, jun. 1997.

Ministério da Educação. Parecer 016/00. Solicitação e celebração de convênio de investimento. Brasília: MEC, 2000.

Ministério da Educação. Convênio 025/2004. Plano de Aplicação. Brasília: MEC, 2004.

Ministério da Educação. Secretaria de Educação Média e Tecnológica. Relatório de gestão: exercício de 2001. Brasília: MEC, 2001. Disponível em: <http://www. mec.gov.br/semtec>. Acesso em: 4 de fev. 2009.

BRAZ, T. Banco Interamericano de Desenvolvimento (BID) no financiamento do Ensino Médio. Série Estudos, Campo Grande, n. 18, p. 143-160, jul./dez. 2004.

O financiamento do ensino médio da Rede Estadual de Mato Grosso do Sul (1996 a 2006). 2008. 288 f. Tese (Doutorado em Educação) - Faculdade de Educação, Universidade Estadual de São Paulo, São Paulo, 2008.

CASTRO, J. A. O Fundo de Manutenção e desenvolvimento do ensino fundamental e de valorização do magistério (Fundef) e seu impacto no financiamento do ensino fundamental. Instituto de Pesquisa e Economia Aplicada, Brasília, n. 604, nov. 1998.

CURY, C. R. J. A educação básica no Brasil. Educação \& Sociedade, Campinas, v. 23, n. 80, p. 169-201, set. 2002.

DAVIES, N. O Fundef e o orçamento da educação: desvendando a caixa preta. Campinas, São Paulo: Autores Associados, 1999.

FERNANDES, M. D. E. Políticas públicas de educação: a gestão democrática na rede estadual de ensino de Mato Grosso do Sul (1991 a 1994). Campo Grande: Editora da UFMS, 2000.

Políticas públicas de educação: o financiamento da rede estadual de ensino de Mato Grosso do Sul (1991 a 1994). 2001. 251 f. Tese (Doutorado em Educação) - Faculdade de Educação, Universidade Estadual de Campinas, São Paulo, 2001.

O estado de Mato Grosso do Sul e os recursos vinculados constitucionalmente para a educação. In: SENNA, E. (Org.). Trabalho, educação e política pública. Campo Grande: UFMS, 2003, p. 221-242.

Gestão da educação básica em Mato Grosso do Sul nos anos 1990. Revista Brasileira de Política e Administração da Educação, Porto Alegre, v. 24, n. 3, p. 517-536, set./dez. 2008.
FERNANDES, M. D. E.; TIBANA, J. M. O impacto do Fundef no financiamento do Ensino Médio em Mato Grosso do Sul (1998-2000). Relatório Final de Iniciação Científica, Campo Grande: UFMS/PIBIc/CNPq, [digitado], 2008.

FERNANDES, M. D. E.; D’AVILA, J. L. A Escola Guaicuru: vivendo uma nova lição: a relação entre gestão e financiamento para o ensino médio. Eccos - Revista Científica, São Paulo, v. 10, n. 2, p. 419-438, jul./dez. 2008.

FONSECA, M. O Projeto Político-Pedagógico e o Plano de Desenvolvimento da Escola: duas concepções antagônicas de gestão escolar. Cadernos Cedes, Campinas, v. 23, n. 61, p. 302-318, dez. 2003.

\section{IBGE. SIDRA. Contagem populacional. 2006.}

IBGE. Censo Demográfico 2000: Características da População e dos Domicílios: Resultado do Universo. Disponível em: <http://www.ibge.gov.br/home/estatistica/populacao/censo2000/default.shtm>. Acesso em: 12 jul. 2010.

INEP. Sinopse Estatística da Educação Básica. Censo Escolar 1998. Brasília: INEP, 1999.

INEP. Resultados do Censo Escolar 2004. Brasília: INEP, 2005.

INEP. Resultados do Censo Escolar 2006. Brasília: INEP, 2007.

LEHER, R. Um novo senhor da educação? A política educacional do Banco Mundial para a periferia do capitalismo. Outubro, São Paulo, n. 3, p. 19-30, 1999.

MATO GROSSO DO SUL. Secretaria de Estado de Educação. A cidadania começa na escola: princípios norteadores. Campo Grande, 1996.

MATO GROSSO DO SUL. Assembleia Legislativa. Emenda Constitucional $n^{\circ}$ 6, de 02 de julho de 1997. Dá nova redação ao artigo 198 da Constituição do Estado. Campo Grande, 1997a. Disponível em: <http://www.ms.gov. br/controle/ShowFile.php?id=26025>. Acesso em: 13 jul. 2010 .

Secretaria de Estado de Finanças, Orçamento e Planejamento. Balanço Anual de Contas de Governo 1996. Campo Grande, 1997b.

Secretaria de Estado de Finanças, Orçamento e Planejamento. Balanço Anual de Contas de Governo 1997. Campo Grande, 1998.

Secretaria de Estado de Educação. Proposta de educação do governo popular de Mato Grosso do Sul - 1999/2002. Série Fundamentos Político-Pedagógicos, Cadernos da Escola Guaicuru, n. 1, Campo Grande, 1999a.

Secretaria de Estado de Finanças, Orçamento e Planejamento. Balanço Anual de Contas de Governo 1998. Campo Grande, 1999b.

Secretaria de Estado de Finanças, Orçamento e Planejamento. Balanço Anual de Contas de Governo 1999. Campo Grande, 2000a.

Secretaria de Estado de Educação. O ensino médio na Escola Guaicuru. Série Fundamentos PolíticoPedagógicos, Cadernos da Escola Guaicuru, n. 2, Campo Grande, 2000b. 
Secretaria de Estado de Educação. Programa especial - cursinho popular. Série fundamentos políticopedagógicos, Cadernos da Escola Guaicuru, n. 6, Campo Grande, 2001a.

Secretaria de Estado de Educação. Curso Estadual Preparatório para Vestibular - CEPV: Histórico. Campo Grande, 2001b. Disponível em: <http://www.sed. ms.gov. br/index. php? inside $=1 \& \mathrm{tp}=3 \&$ comp $=346 \&$ show $=2$ 54>. Acesso em: 01 jun. 2009.

Secretaria de Estado de Receita e Controle. Balanço Anual de Contas de Governo 2000. Campo Grande, 2001c.

Lei n. 2.261, de 16 de julho de 2001. Disciplina sistema de rateio de despesas e apropriação de custos entre órgãos da administração direta, autarquias e fundações, e dá outras providências. Mato Grosso do Sul, 2001d. Disponível em: <http://aacpdappls.net.ms.gov.br/ appls/legislacao/secoge/govato.nsf/448b683bce4ca8470 4256c0b00651e9d/09a5ff853b098e1404256bfd00678458 ?OpenDocument>. Acesso em: 13 jul. 2010.

Secretaria de Governo. Planejamento estratégico do estado de Mato Grosso do Sul (1999 a 2004). Campo Grande, 2001e.

. Secretaria de Estado de Educação. Gabinete do Secretário de Governo. $2^{\circ}$ Termo aditivo ao convênio $n$. 259/00/PROMED. Campo Grande, $2001 \mathrm{f}$.

Secretaria de Estado de Receita e Controle. BaIanço Anual de Contas de Governo 2001. Campo Grande, 2002.

Secretaria de Estado de Receita e Controle. BaIanço Anual de Contas de Governo 2002. Campo Grande, 2003.

Secretaria de Estado de Receita e Controle. Balanço Anual de Contas de Governo 2003. Campo Grande, 2004

Secretaria de Estado de Receita e Controle. BaIanço Anual de Contas de Governo 2004. Campo Grande, 2005.

Secretaria de Estado de educação. Coordenadoria de estatística. Censo 2006. Campo Grande, 2006a.

Secretaria de Estado de Receita e Controle. BaIanço Anual de Contas de Governo 2005. Campo Grande, 2006b.

Constituição (1989). Constituição do Estado de Mato Grosso do Sul. Campo Grande: 2006c. Disponivel em: <http://www.ms.gov.br/controle/ShowFile. php?id=26025>. Acesso em: 13 jul., 2010.

Secretaria de Estado de Fazenda - Auditoria Geral do Estado. Balanço Anual de Contas de Governo 2006. Campo Grande, 2007.

PERONI, V. M. V. Perspectivas da gestão democrática da educação na elaboração de políticas públicas: a constituinte escolar de Mato Grosso do Sul. Série Estudos, Campo Grande, n. 18, p. 49-62, jul./dez. 2004.

PINTO, J. M. de R. O ensino médio. In: OLIVEIRA, R. P. de; ADRIÃO, T. (Orgs.) Organização do ensino no Brasil: níveis e modalidades na Constituição Federal e na LDB. São Paulo: Xamã, 2002. p. 51-76.
RODRIGUES, R. de O. O Programa de expansão e melhoria do ensino médio no Rio Grande do Sul (1999/2002): a afirmação do público na construção das políticas educacionais. 138 f. 2006. Dissertação (Mestrado em Educação) - Universidade Federal do Rio Grande do Sul, Porto Alegre, 2006.

RODRÍGUEZ, A.; HÉRRAN, C. A. Educação secundária no Brasil: chegou a hora. Washington, D. C.: BID/BIRD, 2000.

VIANNA JUNIOR, A. da C. L. O Grupo Banco Mundial e o Banco Interamericano de desenvolvimento no Brasil: a importância do debate sobre os documentos de estratégia de assistência ao país. In: (Org.). A estratégia dos bancos multilaterais para o Brasil: análise critica e documentos inéditos. Brasília: INESC, Rede Brasil, v. 1, 1998. p. 71-93.

Recebido em 26/07/2010

Versão final recebida em 13/09/2010

Aceito em 17/09/2010 